\title{
ANALISIS TEKNOLOGI PEMBANGKIT LISTRIK BIOMASSA PADA SISTEM PENCAHAYAAN PETERNAKAN AYAM DI DESA BORIMATANGKASA KEC. BAJENG BARAT
}

\author{
Adriani $^{1}$ \\ IProgram Studi Teknik Elektro Universitas Muhammadiyah Makassar \\ e-mail: adriani@unismuh.ac.id ${ }^{1}$
}

\begin{abstract}
Chicken Breeding But in relation to the process of raising chickens themselves, one of the biggest expenses of chicken farming is the need for electricity. This study aims to determine the benefits of biomass power generation technology in chicken livestock lighting system. In the utilization of Biomass power plant by using thermoelectric generator, the activities carried out are: Melaukan chicken farm survey, Checking tool, Preparing combustion materials at Biomass power plant, Data collection. The first data obtained is Biomass (Wood). The result is the highest voltage that is $11.0 \mathrm{~V}$ with temperature $44.3^{\circ} \mathrm{C}$ and current $60.0 \mathrm{~mA} \backslash 0.06 \mathrm{~A}$. The second data Biomass The cattle dung (Cow) yield obtained the highest voltage that is $9,04 \mathrm{~V}$ with temperature 42,6 ${ }^{\circ} \mathrm{C}$ and current 65,2 $\mathrm{mA} / 0,065$ A. Data to Three Biomass The cattle dung (Chicken) result obtained yield highest voltage that is $8,00 \mathrm{~V}$ with temperature 42,8 ${ }^{\circ} \mathrm{C}$ and current 31,5 $\mathrm{mA} / 0,0315 \mathrm{~A}$. Selisih perbandingan antara PLN dan Biomassa kayu yaitu $R p 122.019$ kemudian selisih antara PLN dan Biomassa kotoran sapi $R p 122.547$ sedangkan selisih antara PLN dan kotoran ayam yaitu Rp 124.132. burning Wood Biomass more stable in comparison of Livestock Dung, because wood biomass can reach the voltage of $11 \mathrm{~V}$ while the combustion Biomass of cattle dung especially cow dung is less stable and only reaches $9 \mathrm{~V}$ and for Biomass excreta chicken incubation is not stable and its voltage reaches only $7 \mathrm{~V}$.
\end{abstract}

Intisari-Beternak Ayam adalah Salah satu pengeluaran terbesar peternakan ayam adalah kebutuhan listrik. Penelitian ini bertujuan untuk mengetahui manfaat teknologi pembangkit listrik biomassa pada sistem penyahayaan peternakan ayam Dalam pemanfaatan alat pembangkit listrik Biomassa dengan menggunakan generator termoelektrik, kegiatan yang dilakukan : Melaukan survai peternakan ayam, Pengecekan alat, Menyiapkan bahan pembakaran pada alat pembangkit listrik Biomassa, Pengambilan data. Pengambilan data yaitu, Pertama Biomassa (Kayu) adapun hasil yang didapatkan yaitu tegangan paling tertinggi yaitu $11.0 \mathrm{~V}$ dengan suhu 44.3 ${ }^{\circ}$ dan arus 60.0 mA $\backslash$ 0.06A. Data ke dua Biomassa Kotoran ternak (Sapi) hasil yang didapatkan menghasilkan tegangan paling tertinggi yaitu 9,04 V dengan suhu $42,6^{\circ} \mathrm{C}$ dan arus 65,2 mA/ 0,065A. Data ke Tiga Biomassa Kotoran ternak (Ayam) hasil yang didapatkan menghasilkan tegangan paling tertinggi yaitu 8,00 $\mathrm{V}$ dengan suhu $42,8{ }^{\circ} \mathrm{C}$ dan arus $31,5 \mathrm{~mA} /$ 0,0315 A. Selisih perbandingan antara PLN dan Biomassa kayu yaitu Rp 122.019 kemudian selisih antara PLN dan Biomassa kotoran sapi Rp 122.547 sedangkan selisih antara PLN dan kotoran ayam yaitu Rp 124.132. pembakaran Biomassa Kayu lebih stabil di bandingkan Kotoran Ternak,karena Biomassa kayu dapat mencapai tegangan $11 \mathrm{~V}$ sedangkan pembakaran Biomassa kotoran ternak khususnya kotoran Sapi kurang stabil dan hanya mencapai tegangan $9 \mathrm{~V}$ dan untuk Biomassa kotoran ayam pembakarannya tidak stabil dan tegangannya hanya mencapai $7 \mathrm{~V}$.

Intisari- Organisme Biomassa, Generator Termoelektrik, Peltier.

\section{PENDAHULUAN}

Beternak Ayam adalah salah satu bisnis yang memiliki prospek yang sangat baik. Bisnis ini juga menjanjikan konsumen yang sangat besar. Banyak faktor yang menjadikan bisni ini memiliki banyak peminat yaitu selain membutuhkan modal awal yang tidak terlalu banyak bisnis ini juga mempunyai pasar yang sangat besar karna ungags memiliki konsumen peminat yang sangat tinggi terutama jenis unggas yakni ayam. Namun dalam kaitannya proses pemeliharaan ayam itu sendiri, salah satu pengeluaran terbesar peternakan ayam adalah kebutuhan listrik. 
Listrik sendiri digunakan pada saat merupakan teknologi yang paling sederhana penetasan telur dan penerangan. Sedangkan tempat yang cocok untuk membuat kandang ayam yang baik adalah tempat berada pada daerah yang jauh dari pemukiman penduduk - Seperti halnya yang terdapat pada peternakan ayam di Desa Borimatangkasa Kec.Bajeng Barat lokasi kandang ayam broiler harus jauh dari pemikuman penduduk minimal $500 \mathrm{M}$ dan peternakan lain minimal $1 \mathrm{KM}$ lahan yang digunakan harus terbuka (bebas dari pohon dan bangunan lain), agar tidak mengganggu aliran udara di kandang, memiliki sumber air tanah dan jalan mudah dilalui truk kecil. Karna syarat lokasi yang jauh inilah distribusi listrik dari PLN akan susah dan juga tidak stabil (akan sering terjadi pemadaman bergilir, dll). Pemanfaatan energi alternative merupakan salah satu jawaban dari permasalahan tersebut. Salah satunya dengan mengubah kotoran ayam menjadi energi listrik, dengan menggunakan alat pembangkit listrik Biomassa dengan menggunakan Generator Termoeletrik. (Ariantol, 2015).

Secara umum teknologi konversi biomassa menjadi bahan bakar dapat dibedakan menjadi tiga yaitu pembakaran langsung, konversi termokimiawi dan konversi biokimiawi. Pembakaran langsung karena pada umumnya biomassa telah dapat langsung dibakar. Beberapa biomassa perlu dikeringkan terlebih dahulu seperti kayu, gabah, daun dan juga kotoran ternak. (A Arhamsyah, 2010).

Tujuan penelitian ini adalah :

1) Untuk mengetahui memanfaatkan Teknologi pembangkit listrik Biomassa pada sistem pencahayaan peternakan ayam.

2) Untuk mmengetahui jenis Biomassa apa yang digunakan pada pembakaran yang akan dilakukan.

3) Untuk mengetahui selisih pembangkit listrik Biomassa dibanding listrik dari PLN pada peternakan ayam.

Adapun manfaat dari penelitian ini adalah:

1) Memberikan informasi pada penulis dan pembaca mengenai keuntungan yang di dapatkan dari pembangkit listrik Biomassa pada peternakan ayam.

2) Untuk memanfaatkan Biomassa pada sistem pencahayaan peternakan Ayam.

3) Sebagai referensi untuk penelitianpenelitian selanjutnya.

\section{TINJAUAN PUSTAKA}

\section{Peternakan Ayam}

Peternakan adalah kegiatan mengembangbiakkan dan membudidayakan 
ayam ternak untuk mendapatkan manfaat dan hasil dari kegiatan tersebut. Biomassa yang di pakai disini yaitu, Kayu dan kotoran Ternak ( kotoran Sapi dan kotoran Ayam). Limbah atau kotoran ayam ini dipanaskan sampai 250 derajat celcius. Ketika dipanaskan, terjadi proses kimia hingga mengubah limbah itu menjadi bahan yang mirip seperti batu bara.Bahan yang mirip seperti batu bara itulah yang bisa dimanfaatkan menjadi pembangkit listrik. (Rangga, 2015)

\section{Biomassa}

Biomassa adalah bahan biologis yang berasal dari organisme atau makhluk hidup. Menurut kamus besar bahasa Indonesia, Definisi Biomassa adalah jumlah keseluruhan organisme yang terdapat dalam suatu habitat (perairan).

Menurut bungay, Biomassa mempunyai energy kira-kira $1 / 3$ energi batubara per unit massa dan $1 / 4$ energi batubara per unit volume. Konversi teknologi dengan densifikasi dapat merubahnya menjadi masing-masing $2 / 3$ dan 3/4. Sedangkan menurut Bhattacharya mengatakan bahwa densifikasi biomassa mempunyai beberapa keuntungan, yaitu mudah disimpan, mempunyai ukuran dan kualitas yang seragam dan menaikkan nilai kalor per unit volume. (Purwanto, 2012)

\section{Generator Termoelektrik}

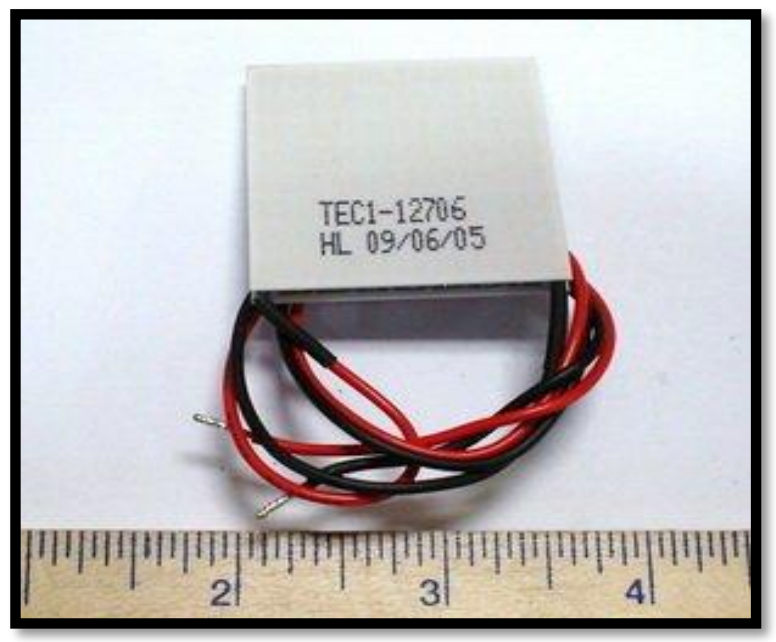

Gambar 1. Skema Cara Kerja Generator Terrmoelektik

Generator Termoelectrik merupakan teknologi pembangkit listrik dengan menggunakan Energi Panas (kalor). Pada alat ini digunakan komponen yang bernama "Peltier".Pada umumnya Peltier adalah keramik yang bisa menghasilkan energi panas dan dingin jika di beri tegangan. Fenomena termoelektrik pertama kali ditemukan tahun 1821 oleh ilmuwan Jerman, Thomas Johann Seebeck. Ia menghubungkan tembaga dan besi dalam sebuah rangkaian. Di antara kedua logam tersebut lalu diletakkan jarum kompas. Ketika sisi logam tersebut dipanaskan, jarum kompas ternyata bergerak. (Efendi, 2016). 


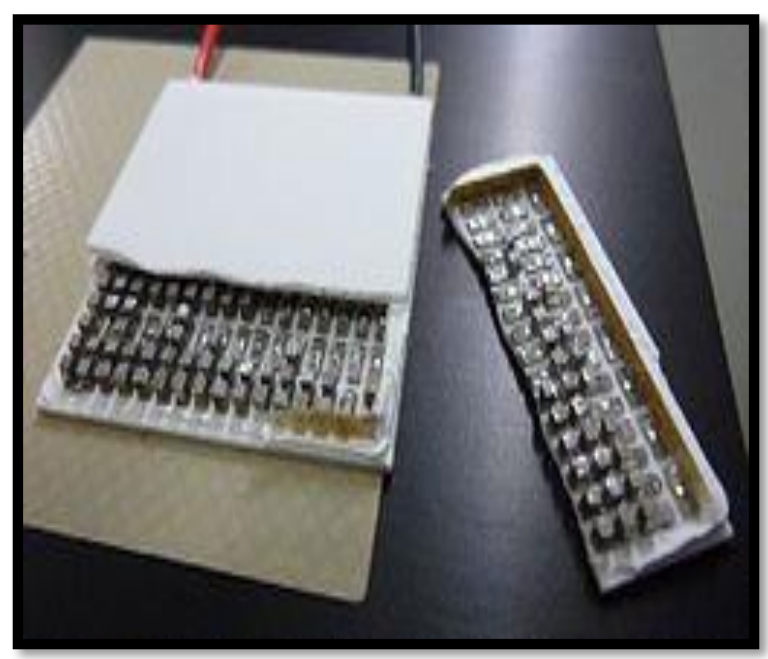

Gambar 2. Keramik (Peltier)

Namun pada Prinsip Termoelectrik, Peltier jika di panaskan salah satu sisinya dan sisi lain panasnya dibuang, maka akan menghasilkan Tegangan. Teknologi termoelektrik bekerja dengan mengonversi energi panas menjadi listrik secara langsung (generator termoelektrik). Cara kerja generator ini adalah apabila ada perbedaan suhu lebih dari 30c diantara kedua sisi peltier maka peltier akan menghasilkan listrik.

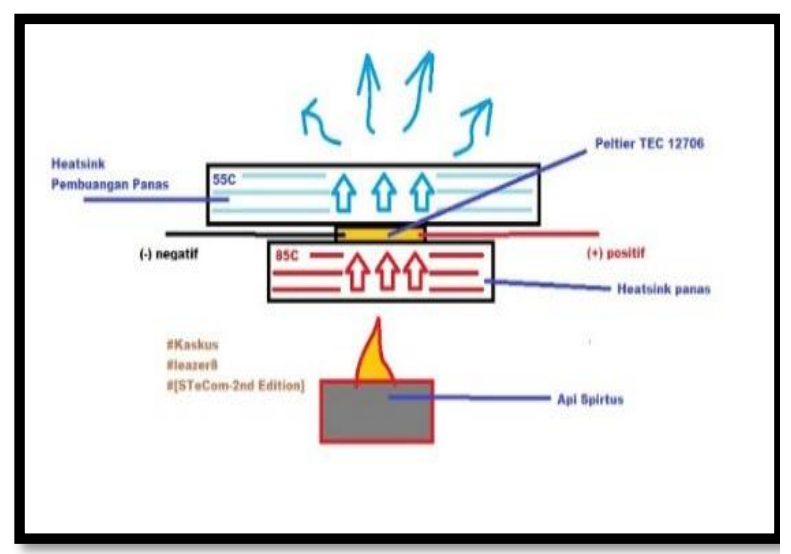

Gambar 3. Skema Cara Kerja Generator Terrmoelektik
Misalnya suhu heatsink yang dipanaskan 85c sedangkan suhu heatsink pembuangan panas 55c sehingga peltier mengalami selisih perbedaan suhu 30c, semakin Jauh selisih suhunya maka listrik yang di hasilkan akan naik, namun sebaiknya jika terlalu panas bisa Overheat dan menyebabkan rusaknya solderan Batangan BIsmuth didalam Peltier. (Puspita, 2017)

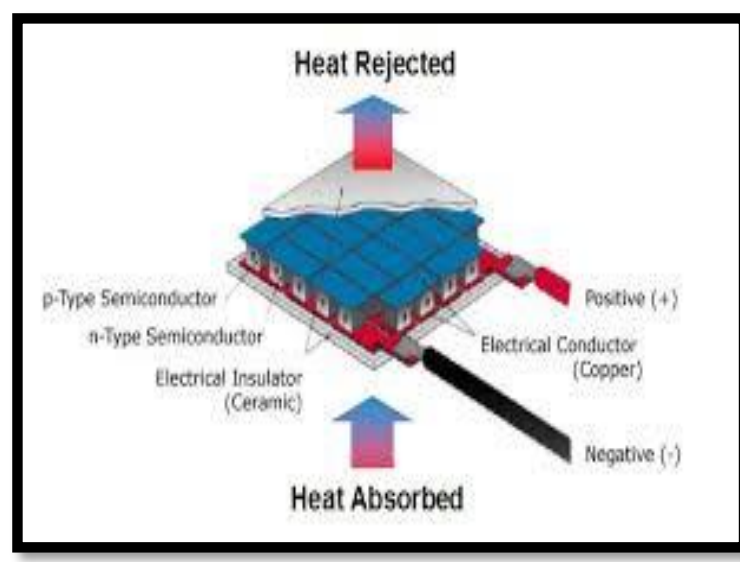

Gambar 4. Simulasi Cara Kerja Generator

\section{Termoelktrik}

Pada gambar diatas merupakan simulasi cara kerja alat, pada gambar Peltier yang diapit oleh kedua heatsink yaitu heatsink panas dan heatsink dingin Api spirtus digunakan untuk memanaskan heatsink kecil (heatsink panas), kemudian energi panas/kalor melewati peltier dan kalor tersebut di serap dan di buang oleh heatsink dingin. Dari perpindahan Kalor tersebut maka peltier akan mengalami perbedaan suhu panas $85 \mathrm{c}$ dan suhu dingin 55c sehingga dari selisih suhu tersebut Peltier akan menghasilkan 
Output tegangan. Teknologi termoelektrik bekerja dengan mengonversi energi panas menjadi listrik secara langsung (generator termoelektrik), atau sebaliknya, dari listrik menghasilkan dingin (pendingin termoelektrik). Untuk menghasilkan listrik, material termoelektrik cukup diletakkan sedemikian rupa dalam rangkaian yang menghubungkan sumber panas dan dingin. Dari rangkaian itu akan dihasilkan sejumlah listrik sesuai dengan jenis bahan yang dipakai. Kerja pendingin termoelektrik pun tidak jauh berbeda. Jika material termoelektrik dialiri listrik, panas yang ada di sekitarnya akan terserap. Dengan demikian, untuk mendinginkan udara, tidak diperlukan kompresor pendingin seperti halnya di mesin-mesin pendingin konvensional. Keberhasilan ini memberikan peluang yang luas dalam aplikasi lainnya. Salah satunya adalah yang dikerjakan Nissan, dengan memanfaatkan panas dari mesin mobil. Seperti kita ketahui, dari 100 persen bahan bakar yang dipakai, hanya sekitar 30 persen yang dipergunakan untuk menggerakkan mobil. (Santi candra, 2017)

Keunggulan dari teknologi Thermoelektrik pada mesin pendingin dari teknologi lainnya adalah:

a. Pendingin Thermoelektrik tidak memiliki bagian yang bergerak, dan karena itu kebutuhan pemeliharaan tidak terlalu penting.

b. Pengujian ketahanan telah menunjukkan kemampuan perangkat untuk Thermoelectrik melebihi 100.000 jam operasi yang stabil di berbagai negara.

c. Temperatur kontrol dari masing-masing bagian dapat dijaga menggunakan perangkat thermoelectric dan dukungan yang sesuai dari circuit..

d. Fungsi dari Pendingin Termoelektrik dalam lingkungan yang terlalu parah, terlalu sensitif, atau terlalu kecil untuk pendinginan konvensional.

e. Pendingin Termoelektrik tidak bergantung pada posisi.

Arah panas pemompaan dalam sistem thermoelectric sepenuhnya dapat dibatalkan. dengan mengubah polaritas dari DC power supply menyebabkan panas yang akan dipompa ke arah-yang dingin kemudian dapat menjadi panas. Mengartikan laju energi yang dihantarkan atau kerja yang dilakukan per satuan waktu.

Adapun rumus yang digunakan dalam penelitian ini yaitu:

1) Rumus daya listrik

$$
\mathrm{P}=\mathrm{V} \times \mathrm{I}
$$


Atau

$\mathrm{P}=I^{2} \times \mathrm{R}$

$\mathrm{P}=V^{2} / \mathrm{R}$

Dimana :

$\mathrm{P}=$ Daya listrik dengan satuan Watt $(\mathrm{W})$

$\mathrm{V}=$ Tegangan listrik dengan satuan Volt

$\mathrm{I}=$ Arus Listrik dengan satuan Ampere (A)

$\mathrm{R}=$ Hambatan dengan satuan $\mathrm{Ohm}(\Omega)$

(Sumber : Buku Rangkaian Listrik, Penerbit Andi)

2) Rumus mencari Harga (PLN dan Alat pembangkit listrik)

a) PLN :

PLN $($ Harga $)=$ Kapasitas Penggunaan $\times$ Lama Penggunaan (Jam) $\times$ Satu Bulan (Hari) $\times$ Harga TTL $(\mathrm{Rp} / \mathrm{kWh})$

b) Alat Pembangkit listrik Biomassa :

Alat $($ Harga $) \quad=$ Kapasitas

Penggunaan $\times$ Lama Penggunaan (Jam)

$\times$ Satu Bulan (Hari) $\times$ Harga TTL

$(\mathrm{Rp} / \mathrm{kWh})$

(Sumber : Ariantol Rangga, dkk. Pemanfaatan teknologi pembangkit listrik Hybrid pada peternakan ayam Desa Sukonolo Kabupaten Malang )

3) Rumus Mencari Daya dan kWh

a) Rumus Daya

$$
\mathrm{P}=\mathrm{V} \times \mathrm{I}
$$

b) Rumus kWh

$\mathrm{kWh}=$ Daya $\times$ Lama Penggunaan
(Sumber: Ariantol Rangga, dkk. Pemanfaatan teknologi pembangkit listrik Hybrid pada peternakan ayam Desa Sukonolo Kabupaten Malang)

\section{METODE PENELITIAN}

Tempat dan waktu penelitian

Tempat pelaksanaan dilakukan di Peternakan Ayam Desa Borimatangkasa Kec.Bajeng Barat. Dengan rencana waktu 4 Bulan.

\section{Alat}

Adapun Alat yang digunakan pada penelitian ini adalah Pembangkit Listrik Biomassa dengan menggunakan Generator Termoelektrik. Adapun komponennya sebagai berikut :

Generator Termoelektrik: Tipe TEC1-12706 Heatsink:1 Buah

Baut: 5 Buah

Lampu :1 Buah

\section{Bahan}

Adapun Bahan yang digunakan pada penelitian ini adalah:

1) Biomassa kayu dan kotoran ternak (kotoran sapi dan kotoran ayam).

2) Buku serta jurnal yang terlampir pada daftar pustaka.

\section{Skema Penelitian}




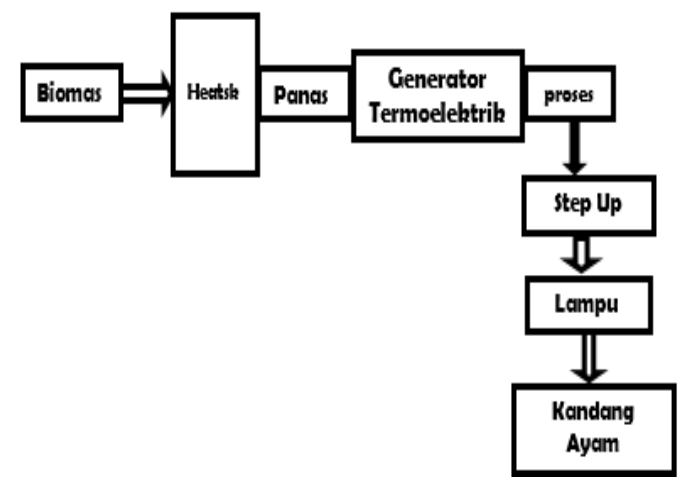

Gambar 4. Diagram Skema Penelitian

\section{Langkah Penelitian}

Secara garis besar tahapan yang dilakukan dalam penelitian ini di tunjukkan pada diagram alir berikut.

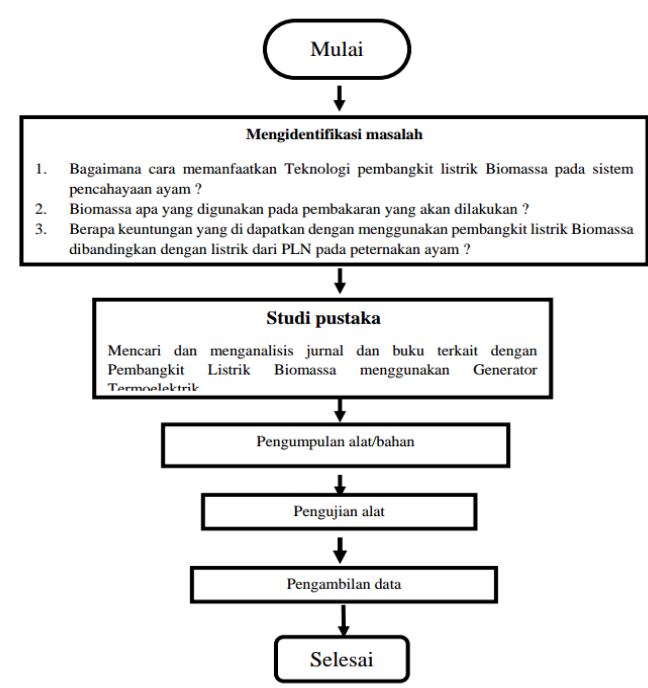

Gambar 5. Diagram Alir Penel

\section{HASIL DAN PEMBAHASAN}

\section{Pembahasan}

Dalam pemanfaatan alat pembangkit listrik

Biomassa dengan menggunakan generator

Vertex EleKtro, Vol. 01, No. 01, Tahun2019

1) Melaukan survai peternakan ayam, survai peternakan ayam dilakukan untuk melihat lokasi peternakan dan sekaligus melakukan wawancara langsung kepada pemilik peternakan mengenai kebutuhan listrik dan biaya yang dikeluarkan setiap bulanannya. Data dari peternakan :

Tabel 1. Data dari peternak Ayam

\begin{tabular}{lccc}
\hline Nama Peralatan & $\begin{array}{c}\text { Tegangan } \\
(\mathrm{V})\end{array}$ & $\begin{array}{c}\text { Arus } \\
(\mathrm{A})\end{array}$ & $\begin{array}{c}\text { Daya } \\
\text { (Watt) }\end{array}$ \\
\hline Lampu 1 (Buah) & 220 & 0.090 & 20
\end{tabular}

Pengecekan alat, bertujuan agar

alat bisa berfungsi dengan baik saat digunakan pada peternakan ayam. Pengecekan alat dilakukan pada setiap komponen alat sebelum komponen alat itu dirangkai. Alat yang digunakan tersebut ialah pembangkit listrik biomassa dengan menggunakan generatortermoelektrik. Pembangkit listrik Biomassa yang ddigunakan ini menggunakan bahan bakar dari Biomassa kayu, Biomassa kotoran ternak (Sapi ddan Ayam). Adapun komponen dari alat tersebut.

Tabel 2. Bahan yang digunakan dalam penelitian

\begin{tabular}{lll}
\hline No & Nama & Bahan Banyaknya \\
\hline 1. & Generator Termoelektrik & 10 Buah \\
\hline 2. & Hedsink & 1 Buah \\
\hline 3. & Kayu & 1 Buah \\
\cline { 2 - 3 } 9 & Baut & 5 Buah \\
\hline 5. & Biomassa & $1 \mathrm{Kg}$ \\
\hline 6. & Lampu & $1 \mathrm{Buah}$ \\
\hline
\end{tabular}


2) Menyiapkan bahan pembakaran pada alat pembangkit listrik Biomassa. Sebelum bahan yang digunakan siap dipakai, terlebih bahan tersebut melalui pengeringan selama kurang lebih 1 bulan lamanya hingga bahan tersebut siap untuk digunakan. Adapun bahan yang digunakan adalah Biomassa kering yang meliputi :

Tabel 3. Biomassa yang digunakan dalam penelitian

\begin{tabular}{lcc}
\hline No & $\begin{array}{c}\text { Jenis } \\
\text { Biomassa }\end{array}$ & Berat \\
\hline 1. & Kayu & $1 \mathrm{Kg}$ \\
\hline 2. & Kotoran Sapi & $1 \mathrm{Kg}$ \\
\hline 3. & Kotoran Ayam & $1 \mathrm{Kg}$ \\
\hline
\end{tabular}

3) Jadwal Pengambilan data di Desa Borimatangkasa Kecematan Bajeng Barat selama kurang lebih 4 Bulan adalah segai berikut :

\begin{tabular}{lll}
\hline 6. & 21 April 2018 & $\begin{array}{l}\text { Pengambilan data biomassa kotoran } \\
\text { ayam }\end{array}$ \\
\hline 7. & 22 April 2018 & Pembuatan Laporan \\
\hline
\end{tabular}

\section{Hasil}

\section{1) Pengambilan Data Pertama Biomassa (Kayu)}

Tabael 5. Data Pengambilan Biomassa Kayu

\begin{tabular}{cccccc}
\hline & Waktu & Suhu & Tegangan & Arus & Daya \\
No & $($ WIB $)$ & $\left({ }^{\circ} \mathrm{C}\right)$ & $(\mathrm{V})$ & $(\mathrm{A})$ & (Watt)
\end{tabular}

\begin{tabular}{cccccc}
\hline 1. & $19: 07$ & $26,3^{\circ} \mathrm{C}$ & 1,00 & 0 & 0 \\
\hline 2. & $19: 08$ & $26,9^{\circ} \mathrm{C}$ & 4.00 & 0 & 0 \\
\hline 3. & $19: 09$ & $27,5^{\circ} \mathrm{C}$ & 5,00 & 0 & 0 \\
\hline 4. & $19: 10$ & $28,9^{\circ} \mathrm{C}$ & 5,02 & 0 & 0 \\
\hline 5. & $19: 11$ & $30,5^{\circ} \mathrm{C}$ & 6,01 & 0 & 0 \\
\hline 6. & $19: 12$ & $32,6^{\circ} \mathrm{C}$ & 8,00 & 0,014 & 0,112 \\
\hline 7. & $19: 13$ & $34,9^{\circ} \mathrm{C}$ & 9,00 & 0,022 & 0,198 \\
\hline 8. & $19: 14$ & $37,5^{\circ} \mathrm{C}$ & 10,1 & 0,034 & 0,343 \\
\hline 9. & $19: 15$ & $41,0^{\circ} \mathrm{C}$ & 10,4 & 0,054 & 0,562 \\
\hline 10. & $19: 16$ & $44,3^{\circ} \mathrm{C}$ & 11,00 & 0,06 & 0,66 \\
\hline 11. & $19: 17$ & $47,6^{\circ} \mathrm{C}$ & 9,04 & 0,0402 & 0,363 \\
\hline
\end{tabular}

Sumber : Hasil Pengukuran dengan bahan bakar kotoran Kayu

Tabel 4. Jadwal pegambilan data

\begin{tabular}{|c|c|c|}
\hline No & Tanggal & Pada Tabel 5 di bawah menjelaskan pada \\
\hline 1. & $\begin{array}{ll}20 \\
2018\end{array}$ & jam 19:07 dengan suhu $26.3{ }^{\circ} \mathrm{C}$ dapat \\
\hline 2. & $\begin{array}{l}26 \\
2018\end{array}$ & 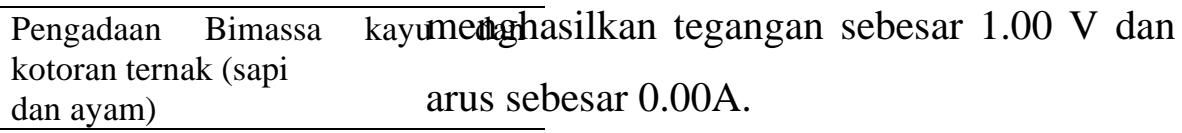 \\
\hline 3. & 01 Maret 2018 & Proses pengeringan Biomassa ${ }^{C}$ ara Penyelesaian : \\
\hline 4. & 19 April 2018 & Pengambilan data biomassa Kayu \\
\hline 5. & 20 April 2018 & $\begin{array}{l}\text { Pengambilan data biomassa Promian I (Sumber : Rumus } \\
\text { sapi }\end{array}$ \\
\hline
\end{tabular}




$$
\begin{aligned}
& \mathrm{V}=11,00 \mathrm{VP}=\mathrm{V} \times \mathrm{I} \\
& \mathrm{I}=0.06 \mathrm{~A} \quad \mathrm{P}=11,00 \mathrm{~V} \times 0.06 \mathrm{~A} \\
& \mathrm{P}=\ldots \ldots ? \quad \mathrm{P}=0.66 \mathrm{Watt}
\end{aligned}
$$

1) Rumus menentukan Harga

a) PLN :

PLN $($ Harga $)=$ Kapasitas Penggunaan $\times$ Lama Penggunaan $(\mathrm{Jam}) \times$ Satu Bulan $($ Hari $) \times$ Harga TTL $(\mathrm{Rp} / \mathrm{kWh})$

(Sumber : Rumus persamaan 2.4)

Jawab :

$\operatorname{PLN}($ Harga $)=0,238 \mathrm{kWh} \times 12$ jam $\times 30$ Hari $\times$ $1467,28(\mathrm{Rp} / \mathrm{kWh})$

$=\operatorname{Rp} 125.716 /$ Bulan

b) Alat Pembangkit listrik Biomassa :

Alat $($ Harga $)=$ Kapasitas Penggunaan $\times$ Lama Penggunaan $(\mathrm{Jam}) \times$ Satu Bulan (Hari) $\times$ Harga TTL (Rp/kWh)

(Sumber : Rumus persamaan 2.5)

Jawab :

$$
\begin{aligned}
\text { Alat }(\text { Harga })= & 0,007 \mathrm{kWh} \times 12 \mathrm{Jam} \times \\
& 30 \text { Hari } \times 1467,28 \\
& (\mathrm{Rp} / \mathrm{kWh}) \\
= & \mathrm{Rp} 3.697 / \text { Bulan }
\end{aligned}
$$

oleh Generator Termoelektrik. Dan pada jam 20:28 menghasilkan tegangan paling tertinggi yaitu $9,04 \mathrm{~V}$ dengan suhu $42,6^{\circ} \mathrm{C}$ dan arus $65,2 \mathrm{~mA} / 0,065 \mathrm{~A}$.

Tabel 6. Data pengambilan biomassa kotoran sapi

\begin{tabular}{cccccc}
\hline No & $\begin{array}{c}\text { Waktu } \\
(\text { WIB })\end{array}$ & $\begin{array}{c}\text { Suhu } \\
\left({ }^{\circ} \mathrm{C}\right)\end{array}$ & $\begin{array}{c}\text { Tegangan } \\
(\mathrm{V})\end{array}$ & $\begin{array}{c}\text { Arus } \\
(\mathrm{A})\end{array}$ & $\begin{array}{c}\text { Daya } \\
\text { (Watt) }\end{array}$ \\
\hline 1. & $20: 19$ & $\begin{array}{c}26,0 \\
{ }^{\circ} \mathrm{C}\end{array}$ & 1,00 & 0 & 0 \\
\hline 2. & $20: 20$ & $\begin{array}{c}26,2 \\
{ }^{\circ} \mathrm{C}\end{array}$ & 1,05 & 0 & 0 \\
\hline 3. & $20: 21$ & $\begin{array}{c}27,2 \\
{ }^{\circ} \mathrm{C}\end{array}$ & 3,00 & 0 & 0 \\
\hline 4. & $20: 22$ & $\begin{array}{c}29,4 \\
{ }^{\circ} \mathrm{C}\end{array}$ & 5,01 & 0,014 & 0,070 \\
\hline 5. & $20: 23$ & $\begin{array}{c}30,7 \\
{ }^{\circ} \mathrm{C}\end{array}$ & 6,02 & 0,0349 & 0,210 \\
\hline 6. & $20: 24$ & $\begin{array}{c}33,6 \\
{ }^{\circ} \mathrm{C}\end{array}$ & 7,00 & 0,0539 & 0,377 \\
\hline 7. & $20: 25$ & $\begin{array}{c}38,3 \\
{ }^{\circ} \mathrm{C}\end{array}$ & 7,08 & 0,054 & 0,382 \\
\hline 8. & $20: 26$ & $\begin{array}{c}40,0 \\
{ }^{\circ} \mathrm{C}\end{array}$ & 8,04 & 0,0561 & 0,451 \\
\hline 9. & $20: 27$ & $\begin{array}{c}42,6 \\
{ }^{\circ} \mathrm{C}\end{array}$ & 9,00 & 0,058 & 0,54 \\
\hline 10. & $20: 28$ & $\begin{array}{c}44,4 \\
{ }^{\circ} \mathrm{C}\end{array}$ & 9,04 & 0,06 & 0,589 \\
\hline 11. & $20: 33$ & $\begin{array}{c}50,0 \\
{ }^{\circ} \mathrm{C}\end{array}$ & 7,00 & 0,0405 & 0,283 \\
& & & & \\
\hline
\end{tabular}

Sumber : Hasil Pengukuran dengan bahan bakar kotoran Sapi

\section{2) Pengambilan Data ke dua}

\section{Biomassa Kotoran ternak (Sapi)}

Cara Penelesaian :

$\mathrm{P}=\mathrm{V}$ x I (Sumber : Rumus persamaan 1)

Pada Tabel IV.6 dibawah menjelaskan pada Jawab :

jam 20:19dengan suhu $26,0 \quad{ }^{\circ} \mathrm{C} \quad$ dapat $=9.04 \quad \mathrm{~V} \quad \mathrm{P}=\mathrm{V}$ x I

menghasilkan tegangan sebesar $1,00 \mathrm{~V}$ dan $=0.065 \mathrm{~A} \quad \mathrm{P}=9.04 \mathrm{~V} \times 0.056 \mathrm{~A}$

arus sebesar 0,00 A. Tegangan dan arus akan $\mathrm{P}^{2}=\ldots . . ? \quad \mathrm{P}=0.587$ Watt

terus naik pada setiap pergantian menit sesuâ) Rumus menentukan Harga

dengan berapa suhu panas yang dikonversi a) PLN 
PLN $($ Harga $)=$ Kapasitas Penggunaan $\times$ paling tertinggi yaitu 8,00 V dengan suhu Lama Penggunaan $(\mathrm{Jam}) \times 42,8^{\circ} \mathrm{C}$ dan arus $31,5 \mathrm{~mA} / 0,0315 \mathrm{~A}$.

Satu Bulan (Hari) $\times$ Harga $\mathrm{TTL}(\mathrm{Rp} / \mathrm{kWh})$

(Sumber : Rumus persamaan 4)

Tabel 7. Data pengambilan biomassa

\begin{tabular}{cccccc}
\multicolumn{7}{c}{ kotoran ayam } \\
\hline \multirow{3}{*}{ No } & Waktu & Suhu & Tegangan & Arus & Daya \\
& (WIB) & $\left({ }^{\circ} \mathrm{C}\right)$ & (V) & (A) & (Watt)
\end{tabular}

Jawab :

$\operatorname{PLN}($ Harga $)=0,238 \mathrm{kWh} \times 12 \mathrm{jam} \times 30$

$$
\begin{aligned}
& \operatorname{Hari} \times 1467,28(\mathrm{Rp} / \mathrm{kWh}) \\
= & \operatorname{Rp} 125.716 / \text { Bulan }
\end{aligned}
$$

b) Alat Pembangkit listrik Biomassa :

Alat $($ Harga $)=$ Kapasitas Penggunaan $\times$ Lama Penggunaan $($ Jam $) \times$ Satu Bulan (Hari) $\times$ Harga TTL (Rp/kWh)

(Sumber : Rumus persamaan 5)

Jawab :

$$
\begin{aligned}
\text { Alat }(\text { Harga })= & 0,006 \mathrm{kWh} \times 12 \mathrm{Jam} \times \\
& 30 \text { Hari } \times 1467,28 \\
& (\mathrm{Rp} / \mathrm{kWh}) \\
= & \mathrm{Rp} 3.169 / \text { Bulan }
\end{aligned}
$$

\section{3) Pengambilan Data ke Tiga Biomassa Kotoran ternak (Ayam)}

Pada Tabel IV.7 dibawah menjelaskan pada jam 19:37 dengan suhu $24,7{ }^{\circ} \mathrm{C}$ dapat menghasilkan tegangan sebesar $1.00 \mathrm{~V}$ dan

\begin{tabular}{|c|c|c|c|c|c|}
\hline 1. & 19: 37 & $\begin{array}{c}24,7 \\
{ }^{\circ} \mathrm{C}\end{array}$ & 1,00 & 0 & 0 \\
\hline 2. & $19: 38$ & $\begin{array}{c}25,6 \\
{ }^{\circ} \mathrm{C}\end{array}$ & 2,00 & 0 & 0 \\
\hline 3. & $19: 39$ & $\begin{array}{c}27,8 \\
{ }^{\circ} \mathrm{C}\end{array}$ & 2,07 & 0 & 0 \\
\hline 4. & $19: 40$ & $\begin{array}{c}28,8 \\
{ }^{\circ} \mathrm{C}\end{array}$ & 4,00 & 0 & 0 \\
\hline 5. & $19: 41$ & $\begin{array}{c}32,2 \\
{ }^{\circ} \mathrm{C}\end{array}$ & 5,01 & 0,00006 & 0,300 \\
\hline 6. & $19: 42$ & $\begin{array}{c}35,1 \\
{ }^{\circ} \mathrm{C}\end{array}$ & 6,05 & 0,0224 & 0,135 \\
\hline 7. & $19: 43$ & $\begin{array}{c}36,4 \\
{ }^{\circ} \mathrm{C}\end{array}$ & 5,02 & 0,0203 & 0,101 \\
\hline 8. & $19: 44$ & $\begin{array}{c}38,5 \\
{ }^{\circ} \mathrm{C}\end{array}$ & 6,00 & 0,022 & 0,132 \\
\hline 9. & $19: 45$ & $\begin{array}{c}41,1 \\
{ }^{\circ} \mathrm{C}\end{array}$ & 7,08 & 0,0283 & 0,200 \\
\hline 10. & $19: 46$ & $\begin{array}{c}42,8 \\
{ }^{\circ} \mathrm{C}\end{array}$ & 8,00 & 0,0315 & 0,252 \\
\hline 11. & $19: 47$ & $\begin{array}{c}47,4 \\
{ }^{\circ} \mathrm{C}\end{array}$ & 6,07 & 0,0208 & 0,126 \\
\hline
\end{tabular}
arus sebesar $0.00 \mathrm{~A}$. Tegangan dan arus akan terunaik pada setiap pergantian menit sesuai dengan berapa suhu panas yang dikonversi oleh Generator Termoelektrik. Dan pada jam 19:47 menghasilkan tegangan

Sumber : Hasil Pengukuran dengan bahan bakar kotoran Ayam

Cara Penyelesaian :

$\mathrm{P}=\mathrm{V}$ x I (Sumber : Rumus persamaan 1)

Jawab :

$\mathrm{V}=8,00 \mathrm{~V} \quad \mathrm{P}=\mathrm{V} \times \mathrm{I}$

$\mathrm{I}=0.031 \mathrm{~A} \quad \mathrm{P}=8,00 \mathrm{~V} \times 0.031 \mathrm{~A}$

$\mathrm{P}=\ldots \ldots ? \quad \mathrm{P}=0.252$ Watt

3) Rumus menentukan Harga

a) PLN :

PLN $($ Harga $)=$ Kapasitas Penggunaan $\times$ Lama Penggunaan (Jam) $\times$ 
Satu Bulan (Hari) $\times$ Harga TTL (Rp/kWh)

(Sumber : Rumus persamaan 4)

Jawab :

$\operatorname{PLN}($ Harga $)=0,238 \mathrm{kWh} \times 12$ jam $\times 30$

Hari $\times 1467,28(\mathrm{Rp} / \mathrm{kWh})$

$=\operatorname{Rp} 125.716 /$ Bulan

b) Alat Pembangkit listrik Biomassa :

Alat $($ Harga $)=$ Kapasitas Penggunaan $\times$

Lama Penggunaan $($ Jam $) \times$

Satu Bulan (Hari) $\times$ Harga

TTL (Rp/kWh)

(Sumber : Rumus persamaan 5)

Jawab :

Alat $($ Harga $)=0,003 \mathrm{kWh} \times 12 \mathrm{Jam} \times$ 30 Hari $\times 1467,28$ (Rp/kWh)

$$
=\operatorname{Rp} 1.584 / \text { Bulan }
$$

\section{PENUTUP}

\section{Kesimpula}

Dari hasil pengujian peralatan Konversi

Energi yang dilaksanakan dari ke 3 bahan bakar Biomassa yang digunakan yaitu Biomassa kayu dan Biomassa kotoran ternak (sapi dan ayam) dapat diperoleh kesimpulan yaitu:

1) Manfaat dari teknologi pembangkit listrik Biomasa yaitu untuk menghemat biaya penggunaan dari PLN dan untuk memanfaatkan limbah yang tidak digunakan dapat dijadikan sebagai pembangkit listrik,

2) Biomassa yang digunakan pada pembakaran ini yaitu Biomassa kayu, biomassa kotoran ayam dan ,biomassa kotoran sapi.

3) Selisih yang didapatkan tanpa menggunakan pembangkit listrik biomassa yaitu harga dari PLN Rp 125.716 sedangkan Harga yang dihasilkan dengan menggunakan pembangkit listrik biomassa Kayu yaitu Rp122.019, menggunakan pembangkit listrik biomassa Kotoran Sapi yaitu Rp 122.547. Dan pembangkit listrik biomassa Kotoran Ayam yaitu Rp 124.132.

\section{Saran}

Kesimpulan dari hsil penelitian maka dapat disampaikan saran untuk kelanjutan dari penelitian yaitu:

1) Perlu ditambahkannya Biomassa lain seperti Kotoran Kuda dan Ampas Padi agar dapat dibandingkan dengan biomassa yang telah diteliti.

2) Perlu digunakannnya pressure cooker atau panci presto untuk memanaskannya dan proses kimia yang terjadi di dalam panci itu mengubah limbah organic menjadi bahan yang berperilaku seperti batu bara 
3) Dalam penyusunan hasil penelitian ini, tentunya masih banyak kekurangan. Oleh karena itu, kritik dan saran yang bersifat membangun sangat kami harapkan

\section{DAFTAR PUSTAKA}

Arhamsyah.,2010. Pemanfaatan Biomassa kayu sebagai sumber Energi Terbarukan. Peneliti Baristand Industri Banjarbaru. Banjarbaru

Ariantol, Rangga., Afif Sulton Wijaya., Zainal Dudik.,dkk.2015.Pemanfaatan Teknologi Pembangkit Listrik Hybrid pada Peternakan Ayam Desa Sukonolo Kabupaten Malang .Fakultas Teknologi Industri Institut Teknologi Nasional Malang.1

Efendi, Selamat.2016. Pengembangan perangkat Konversi Energi panas menjadi Energi Listrik. Fakultas Keguruan an ilmu Pendidikan Universitas Lampung. Bandar Lampung

Purwanto,Rishadi., $\quad$ Rohman.,dkk.2012. PotensiBiomassa Dan simpanan Karbon Jenis-jenis tanaman Berkayu di Hutan Rakyat Desa Nglanggeran,Gunung kidul,Daerah Istimewa Yogyakarta.Fakultas Kehutanan Universitas Gadjah Mada. Yogyakarta

Puspita, Santi candra., hasto sunarno., dan Bachtera indarto.2017. Generator Termoelektrik untuk pengisisan Aki.Departemen fisika-FMIPA, institute Teknologi sepuluh November (ITS). Surabaya
Ridwan., 2015. Mesin Konversi Energi. Univeritas Gunadarma. Depok, Jawa Barat.

Susana, I Gede Bawa., I made Suartika.2017. Konversi Energi Biomassa Kotoran Sapi melalaui Rancangan Biodigester untuk Rumah Tangga. Fakultas Teknik universitas mataram.Mataram

Susana, I Gede Bawa.,2009. Peningkatan Nilai Kalor Biomassa Kotoran Kuda dengan Metode densifikasi dan thermolisis. Fakultas Teknik, Universitas mataram. Mataram

Tajalli, Arif.,2015. Panduan penilaian potensi Biomassa sebagai sumber energy alternativ di Indonesia. Penabulu Aliance

Waspon, anton.1997. Biomassa sebagai pembangkit listrik. Wacana No.9/juliAgustus 1997

Yahya,yasin.2017. Produksi Biogas dari campuran Kotoran ayam, Kotoran sapi, dan rumput gajah mini(Pennisetum purpureum cv.mott) dengan sisstem Batch. Fakultas Pertanian Univeritas Lampung. Bandar Lampung. 